\title{
The Kobe (Hyogo-ken Nanbu), Japan, Earthquake of January 16, 1995
}

\author{
A report of preliminary observations prepared by \\ Hiroo Kanamori \\ California Institute of Technology
}

$\mathrm{T}$ he Kobe earthquake of January 16, 1995, is one of the most damaging earthquakes in the recent history of Japan. This earthquake is also called "The Hyogo-ken Nanbu (Southern part of Hyogo prefecture) earthquake," and the disaster caused by it is referred to as "Hanshin

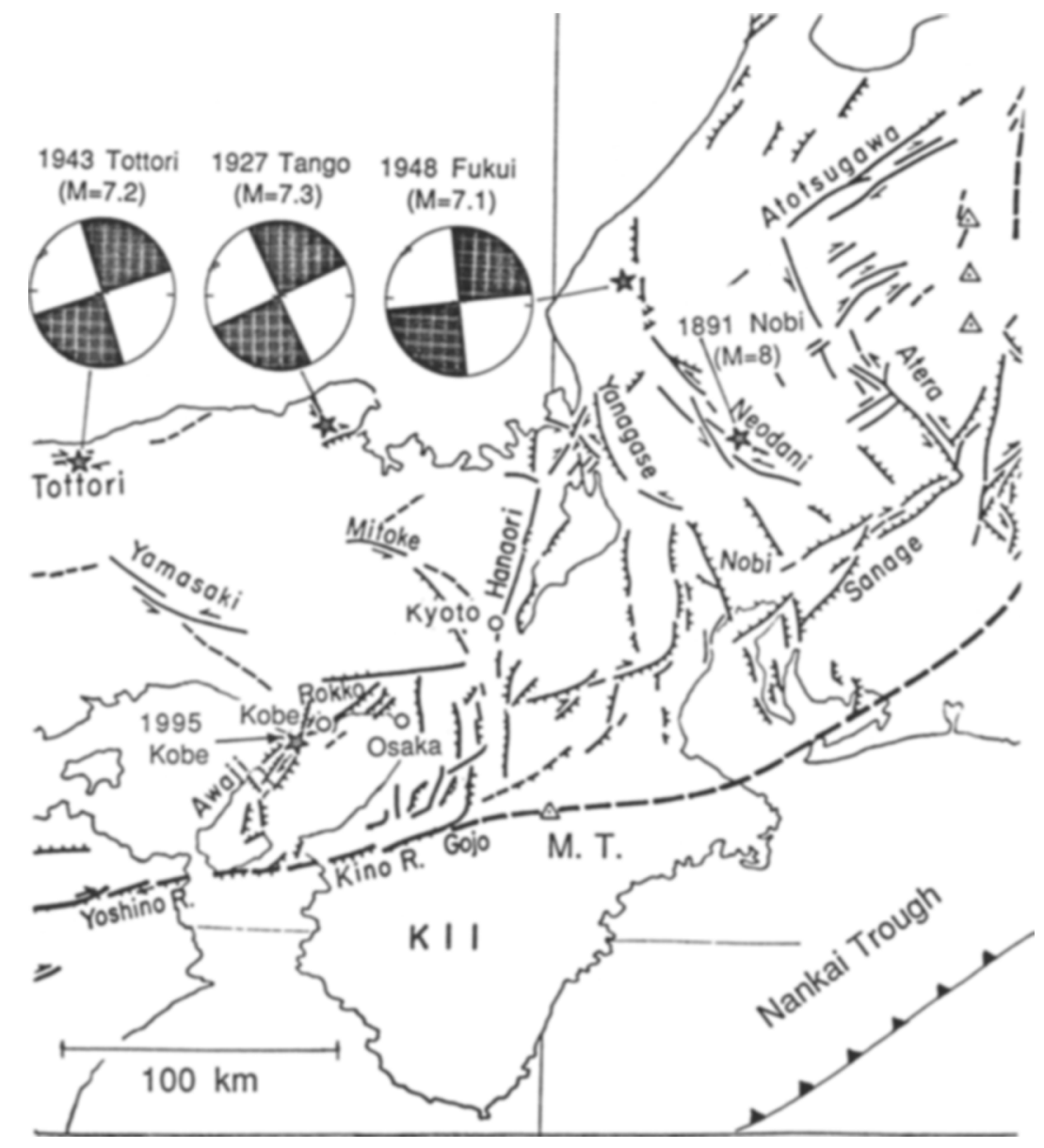

Daishinsai (A major earthquake disaster in the Osaka-Kobe area)." As of January 29, 1995, the casualty toll reached 5,094 dead, 13 missing and 26,798 injured.

This article presents some background on the earthquake and its setting and a summary of some preliminary seismological results obtained by various investigators.

The Japan Meteorological Agency (JMA) located this earthquake at $34.60^{\circ} \mathrm{N}$, $135.00^{\circ} \mathrm{E}$, depth $=22 \mathrm{~km}$, origin time $=$ 05:46:53.9, 1/17/1995 JST, (20:46:53.9, 1/16/ 1995 GMT) with a JMA magnitude $M_{J}=7.2$ (Figure 1). The epicenter is close to the city of Kobe (population, about 1.4 million), approximately $200 \mathrm{~km}$ away from the Nankai trough (the major plate boundary between the Philippine Sea and the Eurasia plates), and about $40 \mathrm{~km}$ from the Median Tectonic Line. In this sense this earthquake can be called an intraplate earthquake. In centralwestern Japan four major intraplate earthquakes have occurred since 1890 (Figure 1): the 1891 Nobi earthquake $(M=8,7273 \mathrm{dead})$, the 1927 Tango earthquake $(M=7.3,2925$ dead), 1943 Tottori earthquake $(M=7.2$, 1083 dead), and the 1948 Fukui earthquake $(M=7.1,3769$ dead). Historically, only 2 earthquakes ( $M>7$ in $868, M \approx 6$ in 1916) have occurred in the vicinity of the Kobe earthquake. (The 868 earthquake is generally believed to have occurred on the Yamasaki fault, about $50 \mathrm{~km}$ northwest of the Kobe earthquake, Figure 1). The source parameters of the last 3 earthquakes are summarized in Kanamori (1973), and the focal mechanisms are shown in Figure 1; they are all similar in size and mechanism.

$\Delta$ Figure 1 The locations of the 1995 Kobe earthquake and the four other large intraplate earthquakes (Nobi, Tango, Tottori, and Fukui) in Japan since 1890. The mechanisms for the Tango, Tottori and Fukui earthquakes are also shown. The base map showing the Quaternary faults in the region is taken from Huzita (1980) and modified. M.T. is the Median Tectonic Line.
Figures 1 and 2a show the Quaternary faults in southwest Japan (Huzita, 1980, Research Group for Active Faults in Japan, 1980). A system of right-lateral faults (Rokko fault zone) running from Awaji Shima (Awaji Island) to Kobe with $\mathrm{NE}-\mathrm{SW}$ strike has been mapped in the epicentral area. Because of the numerous active Quaternary faults and historical 
a.

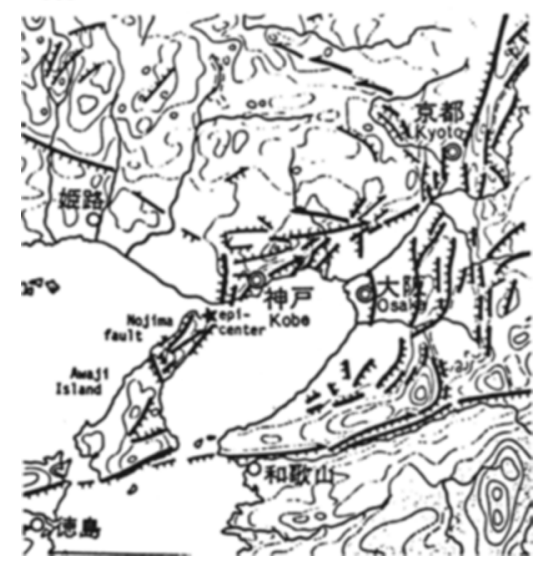

b.

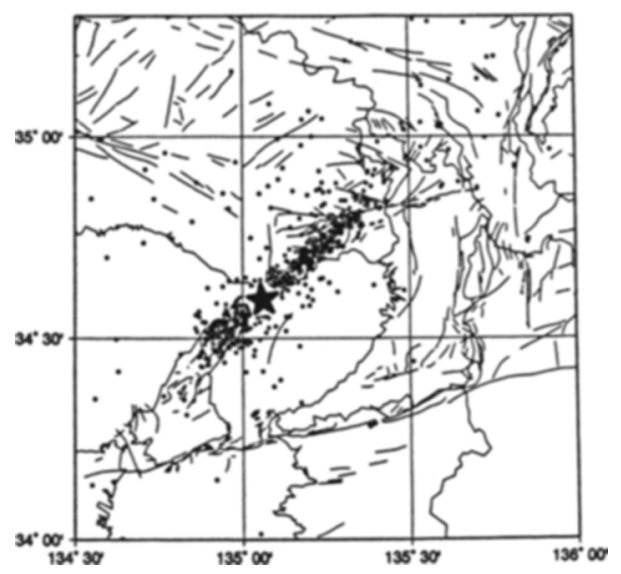

C.

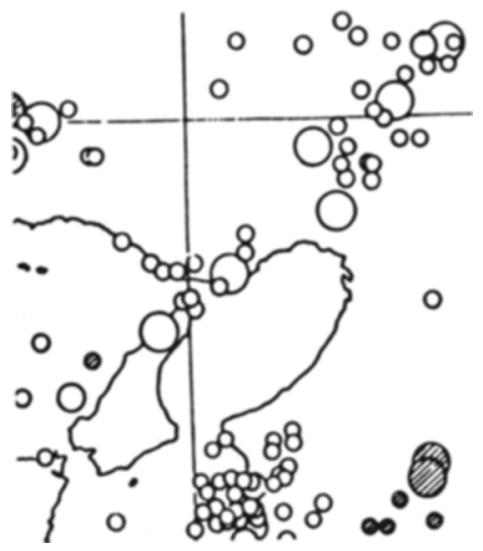

$\Delta$ Figure 2 a) Quaternary faults in the vicinity of the Kobe earthquake (modified from Research Group of Active Faults, 1980). b) Aftershock distribution of the Kobe earthquake determined by the automatic hypocenter location system at the Abuyama Observatory, Disaster Prevention Research Institute (DPRI), Kyoto University. The data are from DPRI, Kyoto University, Wakayama Observatory of the Earthquake Research Institute of Tokyo University, and School of Earth Sciences, Nagoya University. c) The distribution of small earthquakes during the period from 1961 to 1967 compiled by the Wakayama Micro-earthquake Observatory, Tokyo University, Huzita (1969). Most events shown in this figure have $M<5$.

damaging earthquakes, the seismic hazard potential in the Kinki district that includes the Kobe area has been a matter of serious concern (e.g., Oike, 1992). For example, in 1994 The Committee of Earthquake Observation and Research in the Kansai Area (1994) reviewed the potential seismic hazard in the Kinki district, although the fault system on which the Kobe earthquake occurred was not explicitly discussed.

Figure $2 \mathrm{~b}$ shows the aftershocks for the period from Jan.
Kikuchi (1995) using body-waveform inversion. The mechanism is almost pure strike-slip with a seismic moment of $2.5 \times 10^{26}$ dyne-cm $\left(M_{w}=6.9\right)$ and a source duration of 6 to 10 sec. The seismic moments obtained by various investigators range from 1.8 to $3.1 \times 10^{26}$ dyne-cm (HVD, ERI, CIT, NEIS, Univ. Michigan), which gives $M_{w}=6.9$. The difference between $M_{w}=6.9$ and $M_{j}=7.2$ is due to the difference in the method used in the magnitude determination; $M_{w}$ is com17 to Jan. 20 (JST) located using the data from the micro-earthquake networks of Kyoto, Tokyo, and Nagoya Universities (Disaster Prevention Research Institute, Kyoto University, written communication, 1995). The aftershock area extends in NE-SW direction over a distance of about $50 \mathrm{~km}$. The location of the mainshock with respect to the aftershock area suggests bilateral faulting. The geometry of the aftershock area coincides well with the distribution of the fault system shown in Figure 2a. A seismicity map for the period from 1961 to 1967 (Huzita, 1969) shows distinct activity in the epicentral area of the Kobe earthquake (Figure 2c).

A surface rupture of 1 to $1.5 \mathrm{~m}$ was found over a $9 \mathrm{~km}$ section of the Nojima fault (Figure 2a) along the northwestern coast of Awaji Island on Jan. 18 by Nakata et al., (T. Mo $=2.5 \times 10^{* * 26}$ dyne $-\mathrm{cm} \quad \mathrm{Mw}=6.9$ Depth $=8 \mathrm{~km}$ var. $=0.3450$

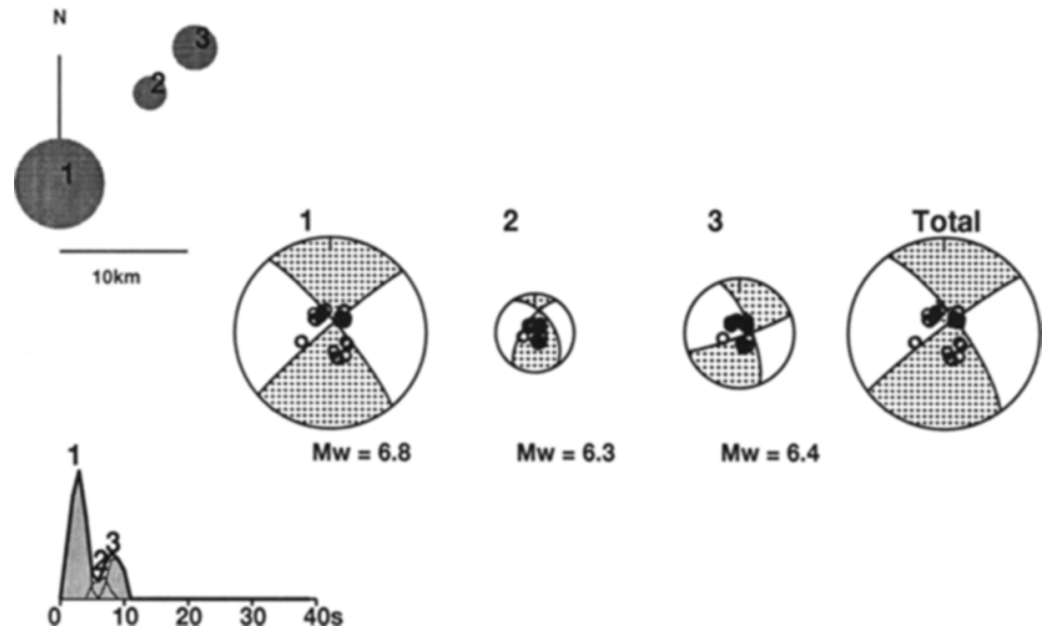

Nakata, K. Yomogida, J. Oada, and T. Sakamoto, written communication, 1995). No distinct surface break has been found yet on the main island near Kobe.

Figure 3 shows the focal mechanism determined by

$\Delta$ Figure 3 The mechanism of the Kobe earthquake (Kikuchi, 1995). The subevent distribution, mechanisms, and the source time function are shown. 


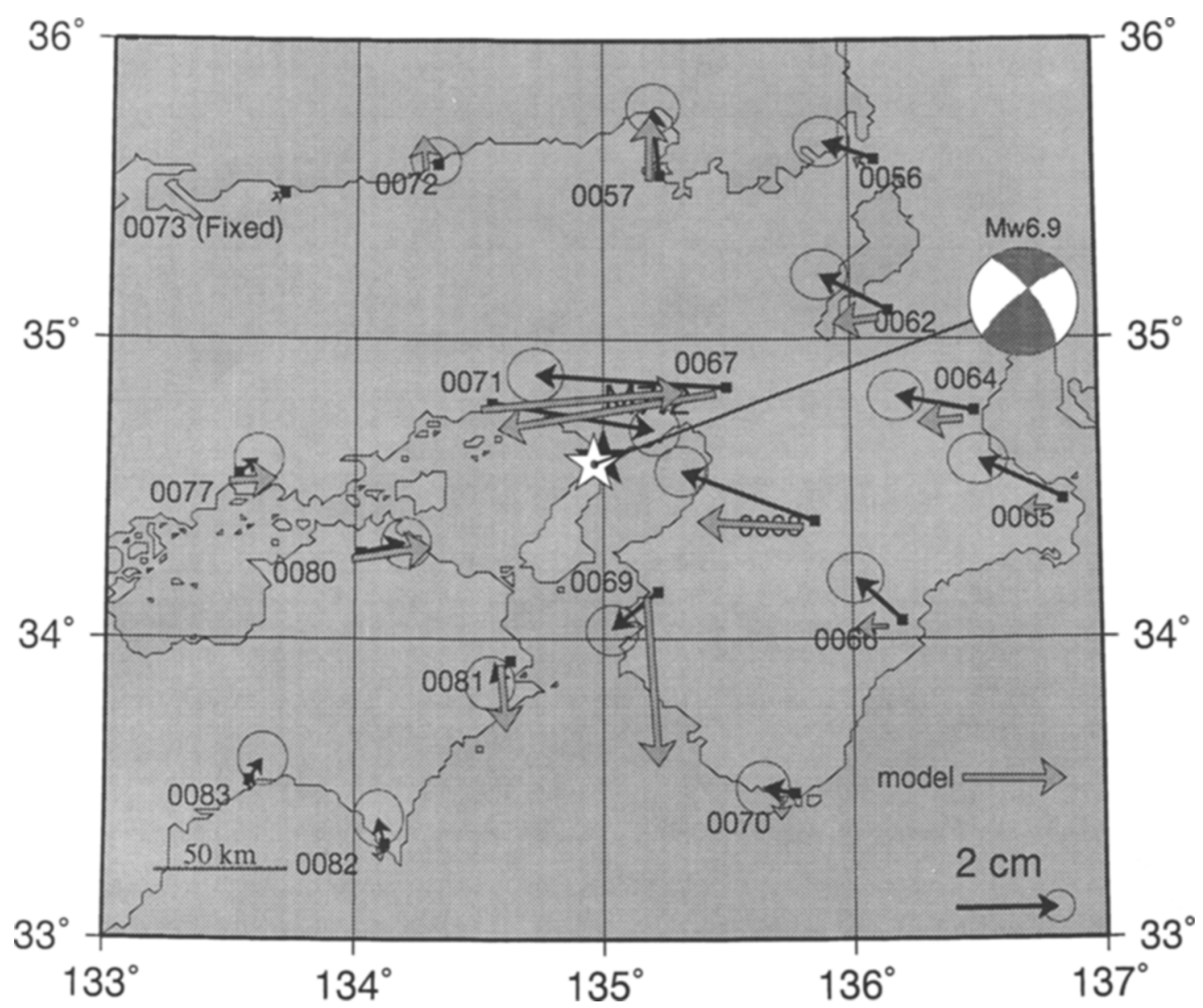

A Figure 4 Horizontal displacements (solid vector) determined by the GSI continuous GPS network, and those computed by K. Hudnut for a fault model determined from seismic data (shaded vector) (fault area=25x15 km², slip=2.11 m).

puted from the seismic moment determined with a detailed source inversion, while $M_{j}$ is determined from the observed amplitudes of regional seismic waves using the traditional empirical method. Kikuchi (1995) located 3 subevents, one near the epicenter and 2 small subevents about $20 \mathrm{~km}$ northeast of it. If the pattern is taken literally, it suggests unilateral faulting, but the first event itself could be bilateral so that the overall rupture could be considered bilateral.

Figures 2 and 3 , taken together, leave little doubt that the source of this earthquake is a shallow bilateral strike-slip fault. From these figures, the rupture area could be estimated as $30 \mathrm{~km}$ to $50 \mathrm{~km}$ (length) $\times 15 \mathrm{~km}$ (width). From this fault area the average slip is 1.1 to $1.9 \mathrm{~m}$ and the stress drop is 14 to 24 bars. The slip and stress drop can be significantly larger than these average values at some locations on the fault plane. The source parameters (magnitude, source dimension, slip, stress drop) of the Kobe earthquake are very similar to those of the 1989 Loma Prieta, California, earthquake.

Figure 4 shows the horizontal displacements of several benchmarks (solid arrows) around the epicenter determined by the Geographical Survey Institute (GSI, Tsuji and Hatanaka, 1995) using their recently deployed continuous GPS network. The shaded vectors on this map indicate displacements computed by $K$. Hudnut (written communication, 1995) using a homogeneous half space and the mechanism determined by Harvard University (HVD CMT solution). Despite the simplicity of the model, the computed displacements are in good agreement with the observed. Minor adjustments of the slip distribution, fault geometry, and the crustal structure would improve the agreement.

To compare the overall character of the Kobe earthquake with other similar-sized earthquakes, Figure $5 \mathrm{com}$ pares the P-wave displacement records for the 1994 Northridge, 1989 Loma Prieta, 1988 Armenia and the 1995 Kobe earthquakes recorded at teleseismic distances. The stations are located away from the $\mathrm{P}$-wave radiation node so that the waveform can be approximately interpreted as the source moment rate (or energy rate) function. In general, the waveforms are similar in duration; the Armenian earthquake exhibits more complexity than the others due to the very complex fault pattern. The reverberations following the P-wave 

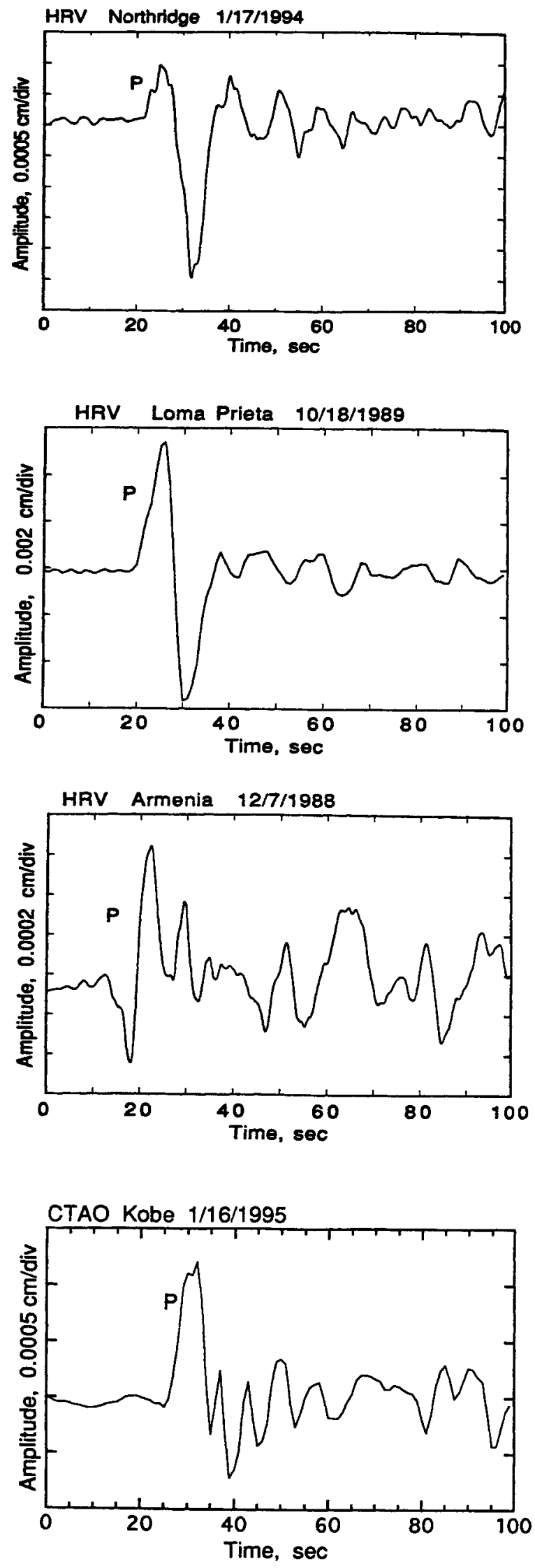

pulse for the Kobe earthquake could be partly due to nearsource structure effects rather than to source complexity.

The ground-motion data released from several organizations (The Committee of Earthquake Observation and Research in the Kansai Area, Japan Rail, Osaka Gas, JMA, Hankyu Railroads, Japan Highways, and Building Research Institute) indicate peak ground-motion accelerations as large as $80 \%$ of $\mathrm{g}$ in Kobe (Figure 6, Koketsu, written communication, 1995). A peak ground-motion velocity exceeding 50 $\mathrm{cm} / \mathrm{sec}$ was reported near Kobe. Although the data are still incomplete, the ground-motion amplitudes observed for the Kobe earthquake seem to be comparable to, or somewhat smaller than, those observed for recent California earthquakes.

The damage caused by this earthquake was extensive. The total number of buildings in the Kobe area was approximately 500,000 (70 to $85 \%$ low-rise residential structures; 10 to $20 \%$ small commercial buildings; 5 to $10 \%$ large commercial and high-rise apartment buildings). The Japanese media reported on January 29 that more than 98,960 buildings were destroyed or damaged. It was reported that only $20 \%$ of the buildings in downtown Kobe were usable after the earthquake, and railways and expressways were severely damaged at several places between Kobe and Osaka. Most of the large commercial buildings, high-rise apartments and the structures supporting elevated highways and railways that sustained damage have been built since World War II, using the design practices and construction similar to those of California.

Most of the deaths and injuries occurred in the collapse of older wood-frame buildings with heavy roofs. Fires caused by leaks of main gas lines and failure of the water supply system aggravated the situation. Within 5 days of the earthquake more than 300,000 people (about $1 / 5$ of the total population) were temporarily homeless. The total loss is currently estimated at $\$ 200$ billion, almost 10 times more than that for the 1994 Northridge, California earthquake.

In summary, the Kobe earthquake is a shallow strike-slip earthquake comparable in size to the 1989 Loma Prieta earthquake. It is also very similar in fault geometry and size to the three other major intraplate earthquakes (Tango, Tottori, and Fukui) which occurred in central-western Japan since 1890 . Although this type of earthquake may be infrequent on a given fault (repeat time of thousands of years), the large population of these faults in this part of Japan results in the relatively frequent occurrence of such earthquakes in the region as a whole. While mapping of Quaternary faults and monitoring of micro-earthquakes are important for understanding the regional seismo-tectonic framework and for long-term land-use planning, reliable short-term earthquake prediction will remain extremely difficult, especially for

\footnotetext{
$\Delta$ Figure 5 (left) Comparison of teleseismic P-wave displacements for the 1994 Northridge, the 1989 Loma Prieta, the 1988 Armenia, and the 1995 Kobe earthquakes.
} 


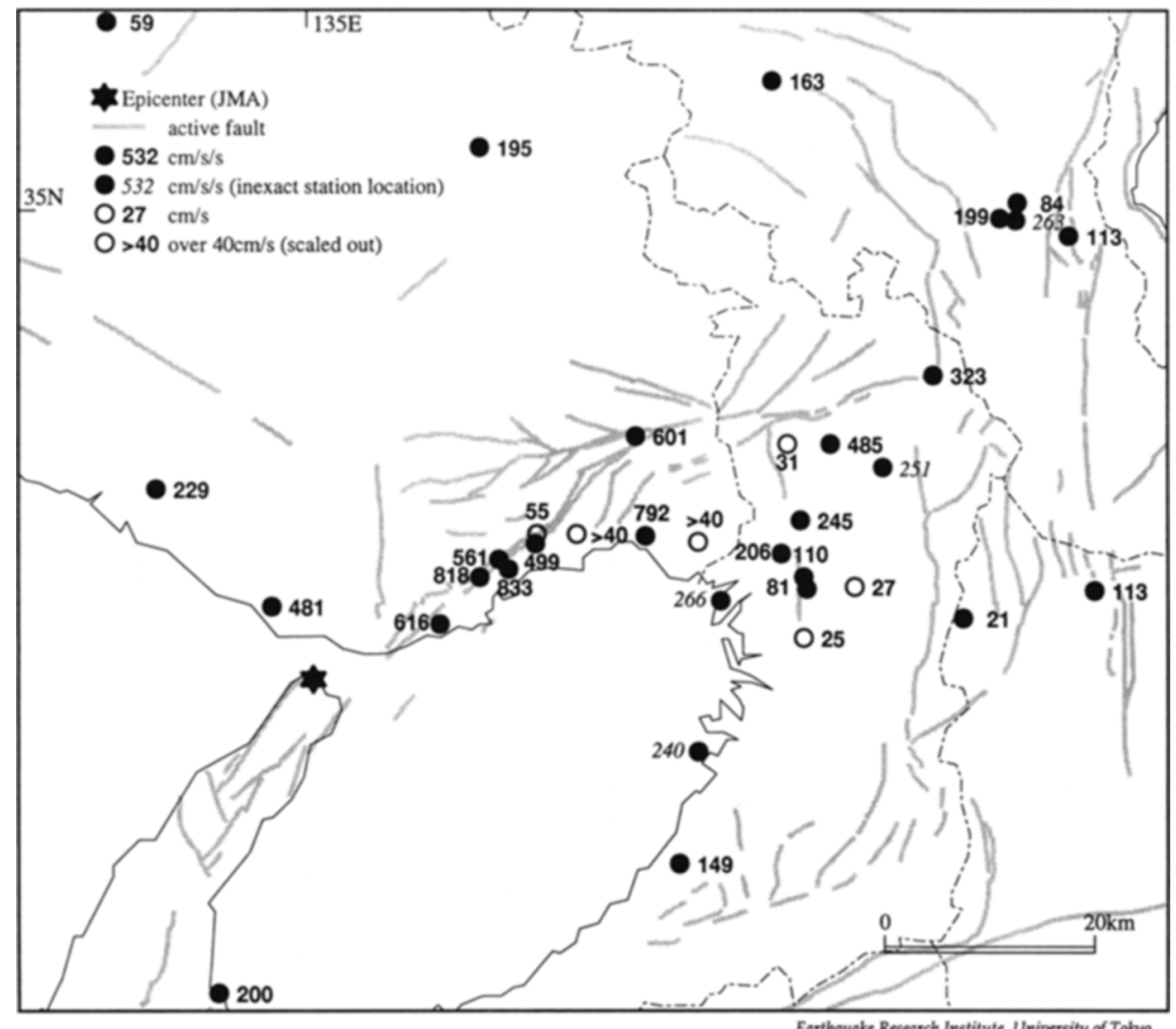

Figure 6 Strong ground
motion distribution compiled at
the Earthquake Research Institute,
University of Tokyo (Koketsu, written
communication, 1995). The data
were provided by The Committee of
Earthquake Observation and
Research in the Kansai Area, Japan
Rail, Osaka Gas, JMA, Hankyu
Railroads, Japan Highways, and
Building Research Institute.

intraplate earthqukes which can occur on any one of numerous faults, each having a very long repeat time.

From the preliminary data presently available, the Kobe earthquake is a typical shallow intraplate earthquake; there is nothing particularly unusual in its source characteristics. The heavy damage is probably due to a combination of the following: the proximity of the rupture zone to a densely populated city, rupture directivity, poor soil conditions, old structures with heavy roofs, fires and failure of water supply systems, and inadequate construction and infrastructure. Since this combination exists in many places of the world, the lessons to be learned from the Kobe earthquake have important implications for seismic hazard reduction strategies in the future. Given the difficulty in predicting earthquakes, an obvious direction is toward: 1) obtaining reliable groundmotion data to be used for better engineering practice; 2) long-term land-use planning; 3 ) implementing infrastructure to issue realtime information for efficient emergency operations. $\mathbf{3}$
I thank M. Kikuchi, P. Somerville, K. Hudnut, H. Tsuji, Y. Hatanaka, K. Koketsu, T. Sato, T. Nakata, Y. Nakamura, H. Kawakatsu, Y. Tanioka, M. Ishida, Y. Hisada and many other investigators for providing me with information and data for this earthquake.

\section{REFERENCES}

Huzita, K., 1969. Tectonic development of southwest Japan in the Quaternary period, Journal of Geosciences, Osaka City University 12, 5370.

Huzita, K., 1976. The Quatemary tectonic stress states of southwest Japan, Journal of Geosciences, Osaka City University 20, 93-103.

Kanamori, H., 1973. Mode of strain release associated with major earthquakes in Japan, Annual Rev. of Earth and Planet. Sci. 1, 213-239.

Kikuchi, M., 1995. The mechanism of the Hyogo-ken Nanbu earthquake of January 17, 1995, in YCU (Yokohama City University) Seismology Report No. 38.

Oike, K., 1992. Japan Earthquake Islands, The Asahi Press, Tokyo, 1-382. Research Group for Active Faults, 1980. Active Faults in Japan, University of Tokyo Press, Tokyo, 1-380.

The Committee of Earthquake Observation and Research in the Kansai Area, 1994. Newsletter No. 2, March 1994.

Tsuji, H, and Y. Hatanaka, 1995. A preliminary result on GPS site displacements associated with the 1995 Hyougo-ken Nanbu earthquake, Anonymous FTP on terras.gsi-mc.go.jp.

The Seismological Society of Japan will join the Seismological Society of America meeting that is to take place in Honolulu in the Spring of 1997. 